\title{
Puerarin 6"-O-xyloside possesses significant antitumor activities on colon cancer through inducing apoptosis
}

\author{
XIAO-LAN ZHANG ${ }^{1}$, BIN-BIN WANG ${ }^{1}$ and JIAN-SHU MO ${ }^{2}$ \\ ${ }^{1}$ Department of Oncology, The First Affiliated Hospital of Zhejiang Chinese Medical University, Hangzhou, Zhejiang 310006; \\ ${ }^{2}$ Department of Oncology, Cixi City Hospital of Traditional Chinese Medicine, Ningbo, Zhejiang 315300, P.R. China
}

Received September 22, 2017; Accepted January 24, 2018

DOI: $10.3892 / \mathrm{ol} .2018 .9364$

\begin{abstract}
Puerarin 6"-O-xyloside (PRX) is a major compound found in the root of the Pueraria lobata (Willd.) Ohwi. The present study aimed to investigate the antitumor activity of PRX against colon cancer and examine its possible mechanism. In the present study, the anti-proliferative effects of PRX against colon cell lines (SW480, LoVo and HCT-116) were evaluated using a Cell Counting Kit-8 assay, and the half maximal inhibitory concentration values of the SW480, LoVo and HCT-11 cells were 37.114, 49.213 and $43.022 \mu \mathrm{g} / \mathrm{ml}$, respectively. Furthermore, the apoptosis of SW480 cells was detected using flow cytometry with Annexin V-fluorescein isothiocyanate/propidium iodide staining. Subsequently, western blot analysis was performed to examine the expression of proteins associated with apoptosis, invasion and metastasis of tumors. The results showed that PRX possessed antitumor activity against colon cancer cell lines in a dose-dependent and time-dependent manner. In addition, PRX significantly upregulated the expression levels of cleaved (c)-caspase-3, c-caspase-9, B-cell lymphoma 2 (Bcl-2), Bcl-2-associated X protein and phosphorylated c-Jun terminal kinase, and downregulated the expression levels of Bcl-2, matrix metalloproteinase (MMP)-3, MMP-9 and vascular endothelial growth factor $(\mathrm{P}<0.01)$. Therefore, the present study demonstrated the PRX exerted antitumor activity against colon cancer cell lines and that the anticancer mechanisms of PRX may be associated with the induction of mitochondria-mediated intrinsic apoptosis, and inhibition of tumor invasion and metastasis. The present study provides a scientific basis for the clinical use of PRX for the treatment of colon cancer.
\end{abstract}

Correspondence to: Dr Bin-Bin Wang, Department of Oncology, The First Affiliated Hospital of Zhejiang Chinese Medical University, 54 Youdian Road, Hangzhou, Zhejiang 310006, P.R. China

E-mail: drwangbinbin@126.com

Key words: puerarin 6"-O-xyloside, colon cancer, antitumor activity, apoptosis, mechanisms

\section{Introduction}

Cancer is the second major cause of mortality around the world, second to cardiovascular diseases (1). The causes of cancer are mainly associated with poor lifestyle behaviors, including smoking, obesity, physical inactivity and poor diet, and changing reproductive patterns (2). In addition, colon cancer is considered the third most commonly diagnosed cancer clinically in the world (3). Currently, the treatment of colon cancer comprises mainly conventional chemotherapy and radiotherapy; however, these therapeutic methods are often accompanied with serious side effects (4). Therefore, it is essential to identify novel effective and safe therapeutic strategies for treating colon cancer. At present, phytotherapy, which uses active anticancer agents isolated from plants to treat cancer, has gained increased attention and has become a widely accepted alternative drug for treating cancer (4). It is reported that etoposide and teniposide, which are extracted from the roots and rhizomes of the Mayapple tree, are used for treating lymphoma, bronchial and testicular cancer (5).

Puerarin, a type of flavonoid, is the major compound in the root of Pueraria lobata (Willd.) Ohwi (P. lobata) (6). It has been widely used in the treatment of cancer, cardiovascular diseases, Parkinson's disease, Alzheimer's disease and diabetes (7). It also exerts protective effects against fever, inflammation, hyperlipidemia and oxidative damage (7). Puerarin injection and other forms (tablet and capsule) of puerarin have been used in clinics extensively in China (8). The hydroxyl group at C-6' of puerarin is often substituted with xylose residues to form puerarin 6"-O-xyloside (PRX; chemical structure shown in Fig. 1) with a high content in the root of P. lobata (9). PRX is one of the major isoflavones of P. lobata (10). Currently, there are numerous investigations on the activities of puerarin. It is reported that PRX has significant antitumor activities against A549 human lung cancer cells (10). However, to the best of our knowledge, there is no relevant report on the effect of PRX against colon cancer.

Therefore, the present study was designed to systemically investigate the antitumor effects of PRX on colon cancer in vitro and examine its possible molecular mechanism. This may be of significant value for the further identification of useful therapeutic agents from this plant to treat diseases clinically. 


\section{Materials and methods}

Reagents and cell lines. PRX (cat. no. JD-24146) was purchased from Shanghai Jindow Biological Technology Co., Ltd. (Shanghai, China). The SW480, LoVo and HCT-116 colon cancer cell lines were obtained from the American Type Culture Collection (Manassas, VA,USA). The DMEM and fetal bovine serum (FBS) were obtained from Invitrogen; Thermo Fisher Scientific, Inc. (Waltham, MA, USA); the Cell Counting Kit-8 (CCK-8) was purchased from Beyotime Institute of Biotechnology (Shanghai, China). Cleaved (c)-caspase-3 (cat. no. ab136812) and c-caspase-9 (cat. no. ab2324) antibodies were purchased from Abcam (Cambridge, MA, USA). B-cell lymphoma 2 (Bcl-2)-associated X protein (Bax; cat. no. ab32503), Bcl-2 (cat. no. ab32124), Bcl-2-associated death promoter (Bad; cat. no. ab32445), c-Jun N-terminal kinase (JNK; cat. no. ab76125), phosphorylated (p)-JNK (cat. no. ab4821), p-Akt (cat. no. ab38449), Akt (cat. no. ab8805), matrix metalloproteinase (MMP)-3 (cat. no. ab38907), MMP-9 (cat. no. ab73734) and vascular endothelial growth factor (VEGF; cat. no. ab11939) antibodies were products of Abcam. Bicinchoninic acid (BCA) protein assay reagent was purchased from Beyotime Institute of Biotechnology (cat. no. P0012S). Silica-gel (100-200 mesh) was purchased from Qingdao Haiyang Chemical Co., Ltd. (Qingdao, China). The Annexin V-fluorescein isothiocyanate (FITC)/propidium iodide (PI) kit was purchased from BD Biosciences (San Jose, CA, USA). All other chemicals used in the present study were of analytical reagent grade.

Cell culture. The SW480, LoVo and HCT-116 colon cancer cell lines were maintained in DMEM supplemented with 10\% FBS and antibiotics (1\% penicillin and $100 \mu \mathrm{g} / \mathrm{ml}$ streptomycin; Beyotime Institute of Biotechnology). The cell lines were cultured in an atmosphere containing $5 \% \mathrm{CO}_{2} / 95 \%$ air at $37^{\circ} \mathrm{C}$.

Determination of cytotoxicity. The cytotoxicity was evaluated using the CCK- 8 assay. A $100-\mu l$ cell suspension $\left(5 \times 10^{5}\right.$ cells $\left./ \mathrm{ml}\right)$ was seeded in 96-well plates and incubated in an atmosphere containing $5 \% \mathrm{CO}_{2} / 95 \%$ air at $37^{\circ} \mathrm{C}$ for $24 \mathrm{~h}$. The cells were then administrated PRX at a series of concentrations $(4,8$, $16,32,64,128$ and $256 \mu \mathrm{g} / \mathrm{ml}$ ) and maintained for $24 \mathrm{~h}$ at $37^{\circ} \mathrm{C}$. The control cells were treated with $10 \mu 1$ DMEM for $24 \mathrm{~h}$ at $37^{\circ} \mathrm{C}$. Subsequently, the CCK- 8 assay was performed to determine the percentage of cell proliferation inhibition $(\mathrm{n}=4)$ by detecting the optical density (OD) at $450 \mathrm{~nm}$ using a microplate reader (Bio-Rad Laboratories, Inc., Hercules, CA, USA). The half maximal inhibitory concentration $\left(\mathrm{IC}_{50}\right)$ values of PRX on the SW480, LoVo and HCT-116 cells were calculated. Additionally, SW480 cells were treated with PRX $(16,32$ and $64 \mu \mathrm{g} / \mathrm{ml})$ for $12,24,36$ and $48 \mathrm{~h}$ to determine the dose-dependent and time-dependent effects of PRX. The inhibitory rate was calculated according to the following formula: $\left[\left(\mathrm{OD}_{\text {control }}-\mathrm{OD}_{\text {treatment }}\right) / \mathrm{OD}_{\text {control }}\right] \times 100$.

Analysis of apoptosis. The apoptotic effect of PRX was detected by ACSCalibur cytometer (BD Biosciences). The SW480 cells $\left(5 \times 10^{5} / \mathrm{ml} ; 2 \mathrm{ml}\right)$ were seeded in 6 -well plates for $24 \mathrm{~h}$ at $37^{\circ} \mathrm{C}$. Subsequently, the cells were treated with 15 , 30 and $60 \mu \mathrm{g} / \mathrm{ml}$ PRX. After $48 \mathrm{~h}$, the cells were trypsinized,<smiles>O=c1c(-c2ccc(O)cc2)coc2c(C3OC(COC4OCC(O)C(O)C4O)C(O)C(O)C3O)c(O)ccc12</smiles>

\section{Puerarin 6"-O-xyloside}

Figure 1. Chemical structure of puerarin 6"-O-xyloside.

washed with PBS, centrifuged for $5 \mathrm{~min}$ at $500 \mathrm{x}$ g at room temperature and stained using the Annexin V-FITC/PI kit (200 $\mathrm{ml}$ Annexin V-FITC and $10 \mathrm{ml}$ PI for every $1 \times 10^{5}$ cells) for $5 \mathrm{~min}$ at room temperature in the dark, according to the manufacturer's protocol.

Western blot analysis. The cells were treated with $\operatorname{PRX}(15,30$ and $60 \mu \mathrm{g} / \mathrm{ml}$ ) for $24 \mathrm{~h}$ at $37^{\circ} \mathrm{C}$. Total protein was extracted from the cells using the cell lysis buffer for western blot analysis and immunoprecipitation (Beyotime Institute of Biotechnology; cat. no. P0013), and the protein concentration was determined using the BCA protein assay reagent. Subsequently, $35 \mu \mathrm{g}$ of protein was separated by $12 \%$ SDS-PAGE and running buffer [0.3\% Tris Base, $1.4 \%$ glycine and 20\% SDS (pH 8.3)]. The proteins were then transferred onto polyvinylidene fluoride membranes. The membranes were blocked with $5 \%$ fat-free dry milk in $1 \mathrm{X}$ TBST (containing $0.1 \%$ Tween-20) for $2 \mathrm{~h}$ at room temperature. The membranes were then incubated at $4^{\circ} \mathrm{C}$ overnight with the following primary antibodies: Bax (dilution 1:1,000), Bcl-2 (dilution 1:1,000), Bad (dilution 1:1,000), c-caspase-3 (dilution 1:1,000), c-caspase-9 (dilution 1:1,000), JNK (dilution 1:1,000), p-JNK (dilution 1:1,000), p-Akt (dilution 1:1,000), Akt (dilution 1:1,000), MMP-9 (dilution 1:1,000), VEGF (dilution 1:1,000), MMP-3(dilution 1:1,000) and GAPDH (dilution 1:2,000). Subsequently, the membranes were incubated with horseradish peroxidase-conjugated secondary antibodies (1:2,000; cat. no. A0286; Beyotime Institute of Biotechnology) at room temperature for $1 \mathrm{~h}$. The proteins were detected using the chemiluminescence ECL kit (Abcam). The signals were quantitated using ImageLab software (version 4.0; Bio-Rad Laboratories, Inc.) on a Chemidoc Imaging instrument. To normalize for protein loading, antibodies directed against GAPDH were used, with protein expression levels expressed relative to GAPDH.

Statistical analysis. The significance of differences between groups was determined by one-way analysis of variance followed by Dunnett's multiple comparisons post hoc test using SPSS software (SPSS for Windows 19.0; IBM SPSS, Armonk, NY, USA). The results are presented as the mean \pm standard deviation. $\mathrm{P}<0.05$ was considered to indicate a statistically significant difference. 


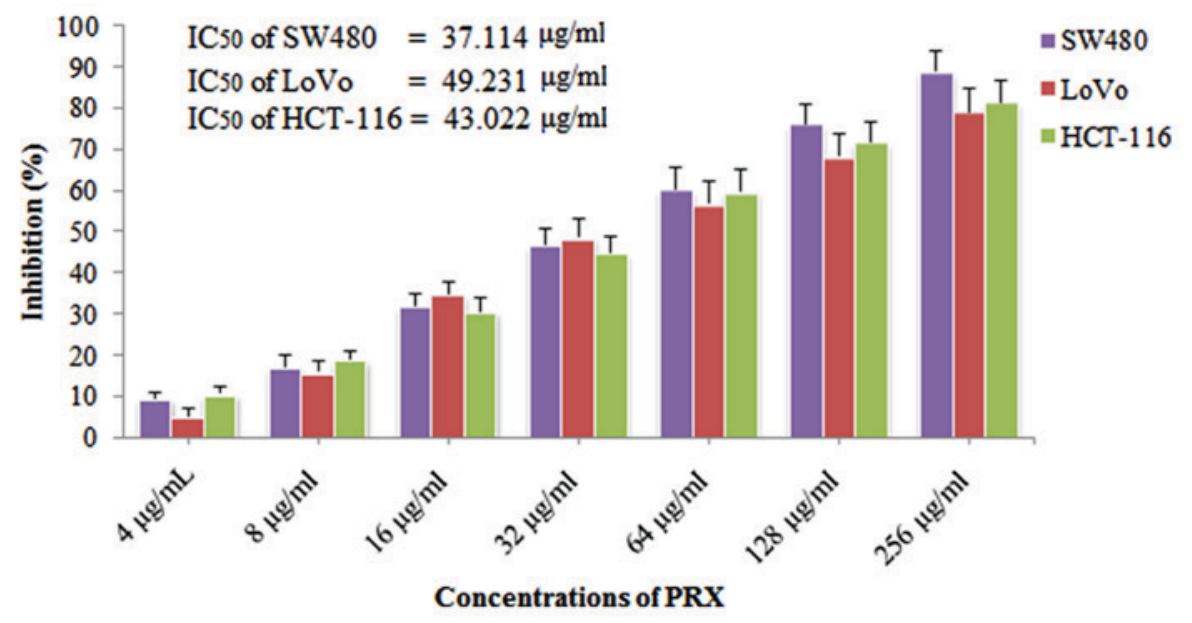

Figure 2. Inhibitory effects of PRX on the proliferation of colon cancer cells. SW480, LoVo and HCT-116 colon cancer cell lines were treated with PRX $(4,8,16,32,64,128$ and $256 \mu \mathrm{g} / \mathrm{ml})$ for $24 \mathrm{~h}$, and cell counting kit- 8 assays were performed to determine the percentage of cell proliferation inhibition (n=4), and $\mathrm{IC}_{50}$ values of PRX on SW480, LoVo and HCT-116 cells were calculated. PRX, puerarin 6"-O-xyloside; $\mathrm{IC}_{50}$, half maximal inhibitory concentration.

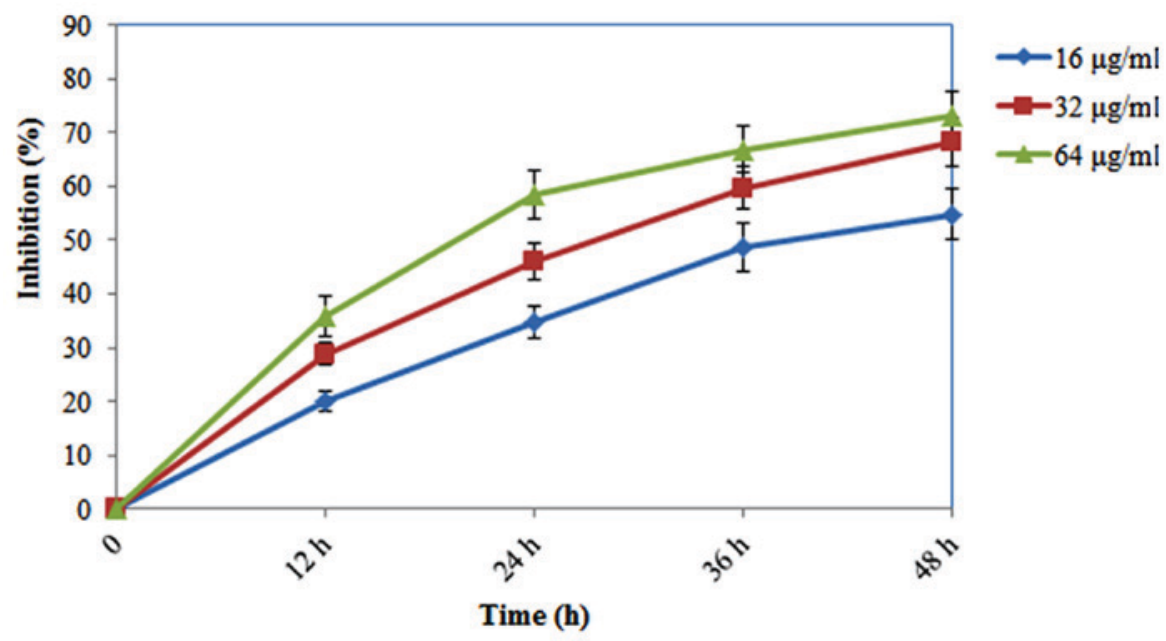

Figure 3. Inhibitory effects of PRX on the proliferation of SW480 cells. SW480 cells were treated with PRX (16, 32 and $64 \mu \mathrm{g} / \mathrm{ml})$ for $12,24,36$ and $48 \mathrm{~h}$, respectively, and Cell Counting Kit-8 assays were performed to determine the percentage of cell proliferation inhibition (n=4). PRX, puerarin 6"-O-xyloside.

\section{Results}

Inhibitory effects of PRX on colon cancer. As shown in Fig. 2, PRX exerted marked inhibitory effects on the three colon cell lines (SW480, LoVo and HCT-116). The $\mathrm{IC}_{50}$ values of the SW480, LoVo and HCT-116 cells were 37.114, 49.231 and $43.022 \mu \mathrm{g} / \mathrm{ml}$, respectively. It was shown that PRX exerted the highest anti-proliferative effect on the SW480 cells, therefore, the SW480 cell line was selected from the three cell lines for further experiments. In addition, as shown in Fig. 3, PRX (16, 32 and $64 \mu \mathrm{g} / \mathrm{ml}$ ) exhibited dose-dependent and time-dependent cytotoxic effects against the SW480 cells.

Pro-apoptotic effect of PRX on SW480 cells. The results of the cell viability experiment indicated that PRX exerted notable antitumor activity against the colon cancer cells. To determine whether the anticancer activity of PRX was associated with apoptosis, the apoptosis induced by PRX was determined by staining with Annexin V-FITC/PI followed by flow cytometric analysis. It was found, as shown in
Fig. 4A-E, that the number of apoptotic cells was increased gradually by treating the cells with increased concentrations of $\operatorname{PRX}(15,30$ and $60 \mu \mathrm{g} / \mathrm{ml})$. These results showed that PRX induced the death of colon cancer cells due to the induction of apoptosis.

Effects of PRX on the protein expression of caspase-3, caspase-9, Bad, Bax and Bcl-2 in SW480 cells. As shown in Fig. 5, the expression levels of caspase-3 and caspase- 9 were upregulated gradually following treatment with increased concentrations of $\operatorname{PRX}(15,30$ and $60 \mu \mathrm{g} / \mathrm{ml} ; \mathrm{P}<0.01)$. In addition, as shown in Fig. 6, the expression levels of Bad and Bax were significantly increased in a concentration-dependent manner, whereas that of Bcl-2 was significantly decreased $(\mathrm{P}<0.01)$. These results demonstrated that $\mathrm{PRX}$-induced apoptosis of SW480 cells may be associated with the mitochondria-mediated apoptotic pathway.

Effects of PRX on the protein levels of PRX on JNK, p-JNK, $p$-Akt and Akt in SW480 cells. To examine other potential 

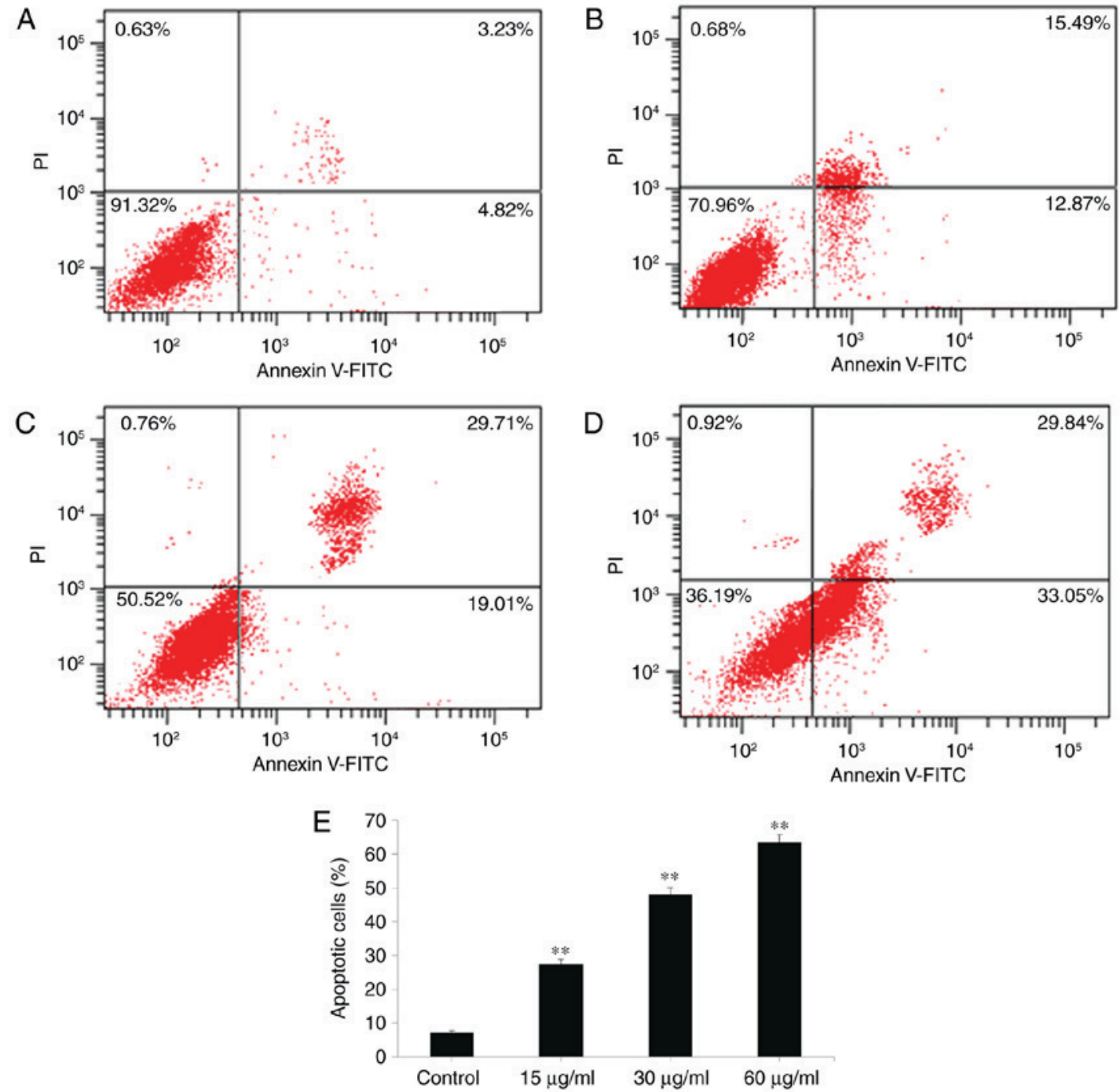

Figure 4. Apoptosis-inducing effects of PRX on SW480 cells. Apoptotic assay using flow cytometry. (A) Control group. The SW480 cells treated with PRX at (B) 15 , (C) 30 and (D) $60 \mu \mathrm{g} / \mathrm{ml}$ for $24 \mathrm{~h}$. The cells were then stained with Annexin V-FITC/PI and were detected by flow cytometric analysis. (E) Statistical analysis of apoptosis. Data are expressed as the mean \pm standard deviation $(\mathrm{n}=4) .{ }^{* *} \mathrm{P}<0.01$ vs. Control. PRX, puerarin 6"-O-xyloside; FITC, fluorescein isothiocyanate; PI, propidium iodide.

mechanisms underlying the effect of PRX on the SW480 cells, the expression levels of proteins associated with the JNK/Akt signal pathway were detected, including JNK, p-JNK, p-Akt and Akt. As shown in Fig. 7, PRX had no significant effect on JNK, p-Akt or Akt (P>0.05). However, PRX (15, 30 and $60 \mu \mathrm{g} / \mathrm{ml}$ ) significantly upregulated the expression of p-JNK $(\mathrm{P}<0.01)$ in a dose-dependent manner, compared with that in the control group.

Effects of PRX on the protein expression of MMP-9, VEGF and MMP-3 in SW480 cells. To examine other possible mechanisms underlying the antitumor activities of PRX on SW480 cells, the expression of proteins associated with tumor invasion and metastasis were detected in the present study. The effects of PRX on the expression levels of MMP-3, MMP-9 and VEGF are shown in Fig. 8. It was found that PRX significantly decreased the expression levels of MMP-9 and VEGF in a concentration-dependent manner $(\mathrm{P}<0.01)$. Additionally, the expression of MMP-3 was downregulated following treatment with PRX (30 and $60 \mu \mathrm{g} / \mathrm{ml}, \mathrm{P}<0.01$ ).

\section{Discussion}

The present study is the first, to the best of our knowledge, to systemically investigate the antitumor effect of PRX on colon cancer cell lines in vitro. The results showed that PRX exerted significant anticancer effects against colon cancer cells in vitro through the induction of mitochondria-mediated intrinsic apoptosis and through inhibiting the invasion and metastasis of tumor cells.

It has been reported that plant-derived medicines are safer than synthetic drugs (11), and they have also been demonstrated to be effective in the treatment of various diseases, particularly those that cannot be treated by modern synthetic drugs (12). Therefore, the aim of the present study was to investigate the antitumor activities of PRX isolated from the root of the P. lobata.

Uncontrolled cell proliferation and insufficient apoptosis may be considered primary causes of cancer (13). Apoptosis is a physiological cell suicide process and is regulated by a series of biochemical events that eventually result in cell death $(14,15)$. In addition, apoptosis is considered to be an ideal 

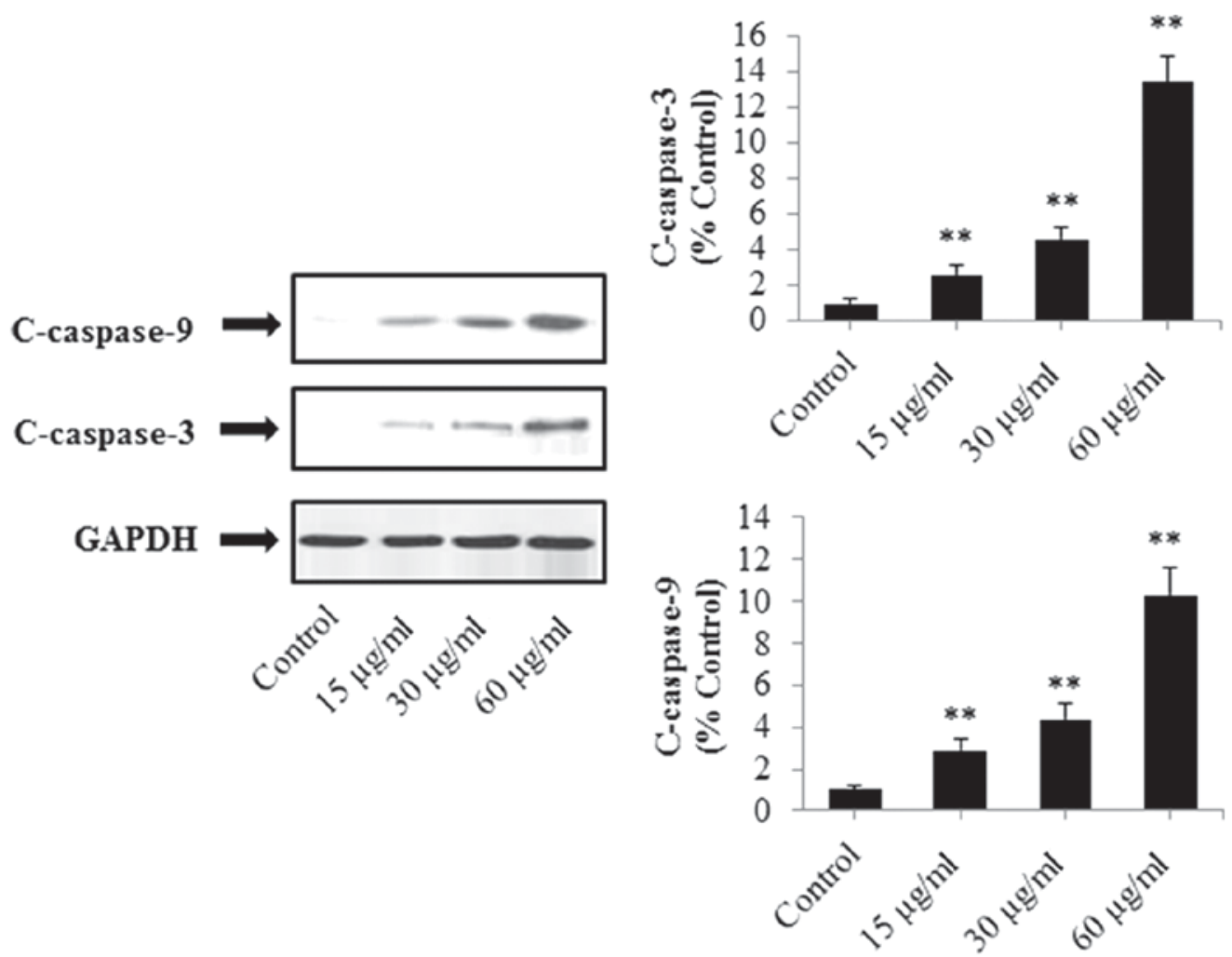

Figure 5. Regulatory effects of PRX on c-caspase-3 and c-caspase-9. Cells were treated with PRX for $24 \mathrm{~h}$, following which total proteins were extracted and subjected to western blot assays. GAPDH was used as an internal control. Data are expressed as the mean \pm standard deviation $(n=4) .{ }^{* *} \mathrm{P}<0.01$ vs. Control. PRX, puerarin 6"-O-xyloside; c-caspase-3, cleaved caspase-3; c-caspase-9, cleaved caspase-9.
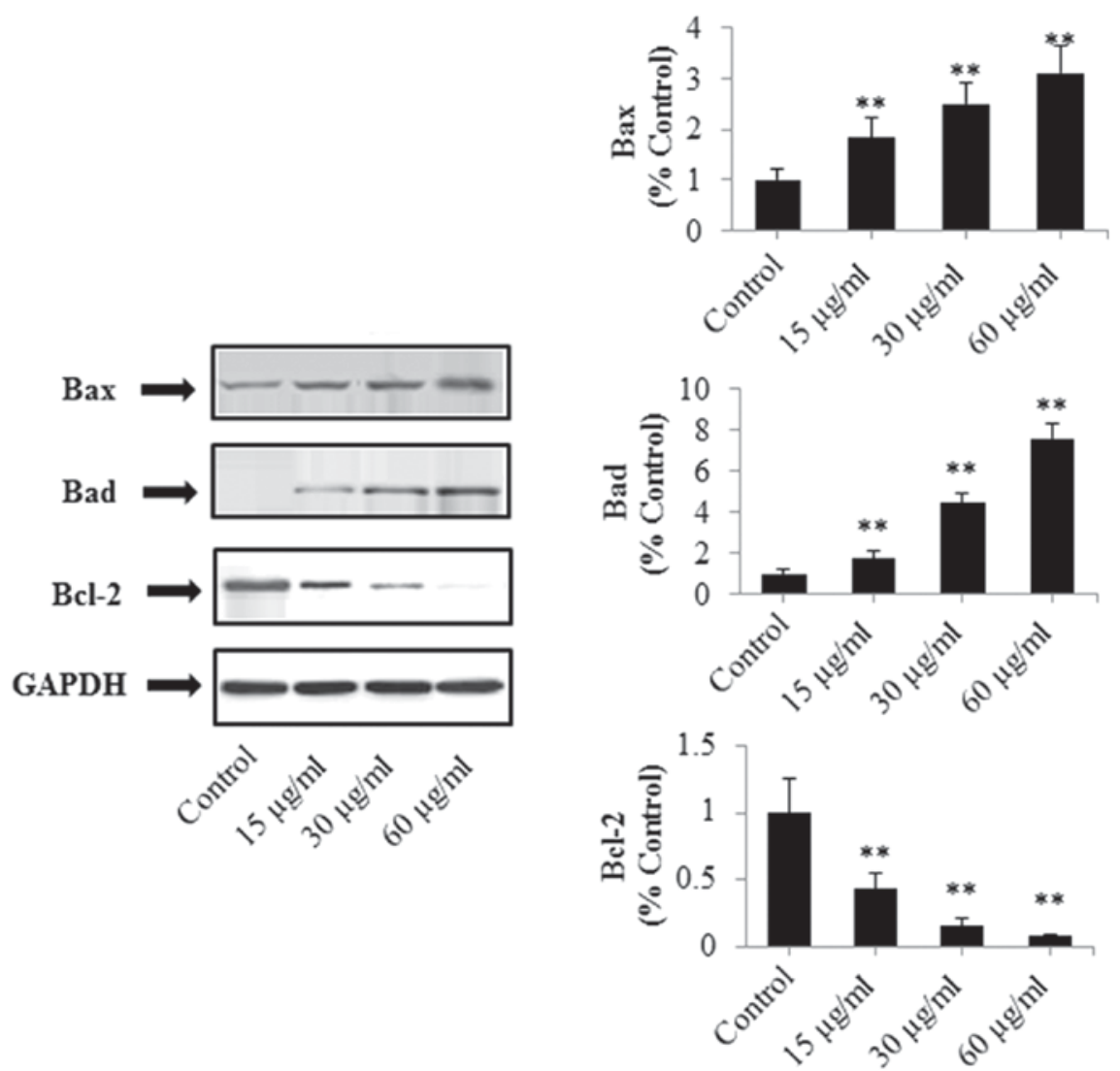

Figure 6. Regulatory effects of PRX on Bax, Bad and Bcl-2. Cells were treated with PRX for $24 \mathrm{~h}$, following which total proteins were extracted and subjected to western blot assays. GAPDH was used as an internal control. Data are expressed as the mean \pm standard deviation $(\mathrm{n}=4){ }^{*}{ }^{* *} \mathrm{P}<0.01 \mathrm{vs}$. Control. PRX, puerarin 6"-O-xyloside; Bcl-2, B-cell lymphoma 2; Bax, Bcl-2-associated X protein; Bad, Bcl-2-associated death promoter. 

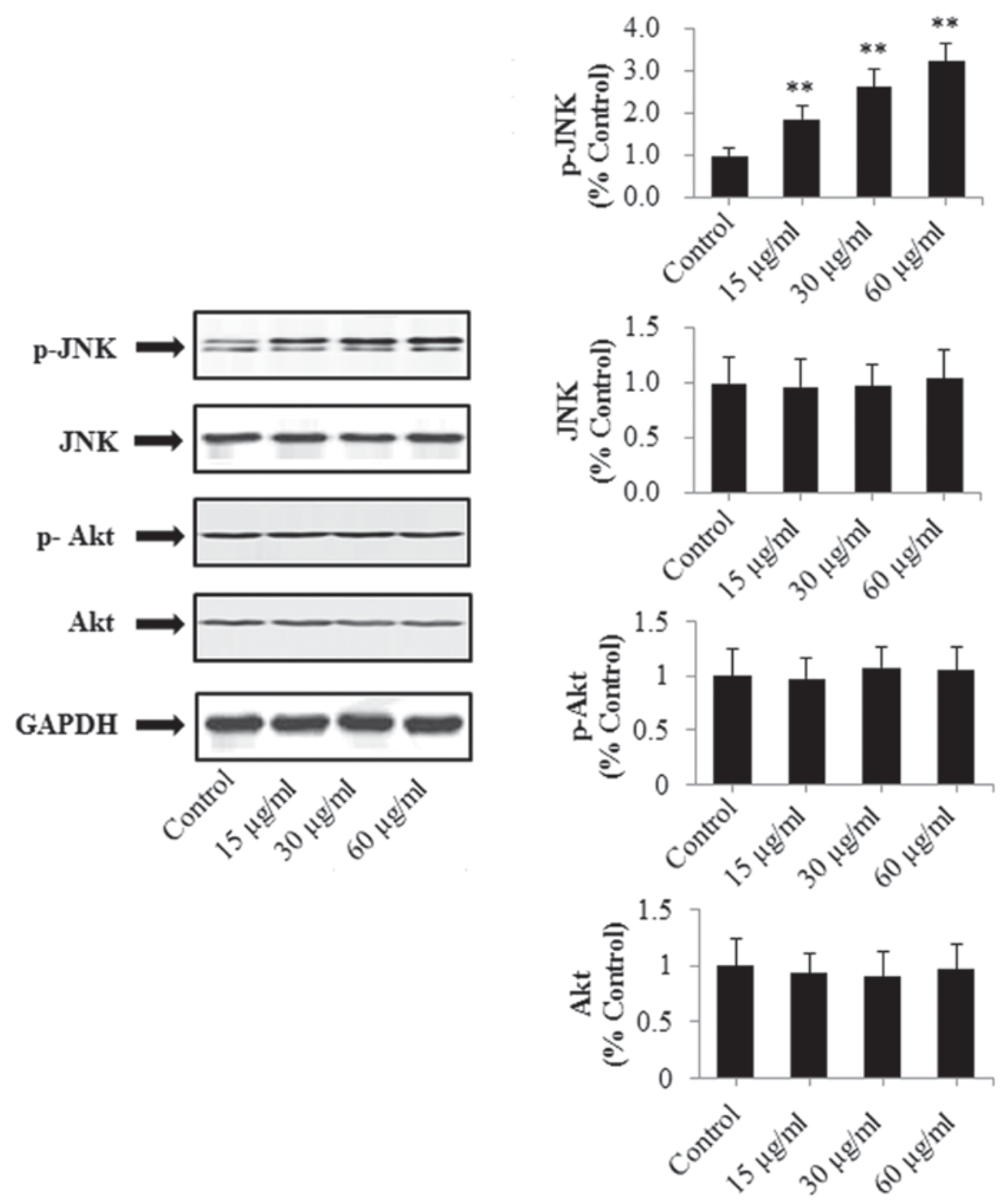

Figure 7. Regulatory effects of PRX on p-Akt, Akt, p-JNK and JNK. Cells were treated with PRX for $24 \mathrm{~h}$, following which total proteins were extracted and subjected to western blot assays. GAPDH was used as an internal control. Data are expressed as the mean \pm standard deviation $(\mathrm{n}=4) .{ }^{* *} \mathrm{P}<0.01$ vs. Control. PRX, puerarin 6"-O-xyloside; JNK, c-Jun N-terminal kinase; p-, phosphorylated.

target for cancer therapy (16). In the present study, PRX exhibited significantly pro-apoptotic effects against SW480 cells. Mitochondria-mediated apoptosis is considered to be a major apoptotic pathway (17). Previous investigations have demonstrated that caspase family proteins are important in apoptosis and inflammatory responses (18). Caspase-9 is considered to be the initiating caspase in the caspase cascade reaction, and activated by cytochrome $c$ (19). Caspase-3 activated by caspase- 9 is a crucial death protease and is considered to be a bio-marker for identifying whether cells are undergoing apoptosis $(20,21)$. Additionally, the Bcl-2 family proteins are crucial in mitochondria-mediated apoptosis, and are considered the initial regulatory step in the induction of mitochondrial apoptosis (22). In the Bcl-2 family, Bcl-2, Bax and Bad are considered to be apoptosis-associated proteins. The function of $\mathrm{Bcl}-2$ is to bind and suppress the other pro-apoptotic relevant proteins of the Bcl-2 family; however, Bax and Bad directly promote the release of cytochrome $c$ into the cytoplasm and inhibit anti-apoptotic Bcl-2 proteins (23). The results of the present study demonstrated that treatment of SW480 cells with PRX resulted in a significant upregulation in the expression levels of of c-caspase-3, c-caspase-9, Bad and Bax, and the downregulation of Bcl-2. These findings showed that PRX induced mitochondria-mediated apoptosis in the SW480 colon cancer cell line.

JNKs can bind to and phosphorylate c-Jun on Ser-63 and Ser-73 within its transcriptional activation domain. p-JNK can modify the activity of proteins that reside in the mitochondria or act in the nucleus (24). In addition, JNK can lead to cell apoptosis via triggering the release of cytochrome $c$ from the mitochondria into the cytoplasm and triggering the caspase cascade reactions $(24,25)$. Akt is a serine/threonine-specific protein kinase, which is important in apoptosis and cell proliferation. Activated Akt inhibits several pro-apoptotic factors, including Bad and procaspase-9 (23). The results of the present study indicated that PRX significantly upregulated the expression levels of p-JNK, which indicated that the mitochondria-mediated apoptosis induced by PRX may be associated with the Akt/JNK signaling pathway.

MMPs are important in the degradation of extracellular matrix (ECM) components, which is important in tumor invasion and metastasis (26,27). MMP-3 and MMP-9 are the important proteases involved in cancer invasion and 

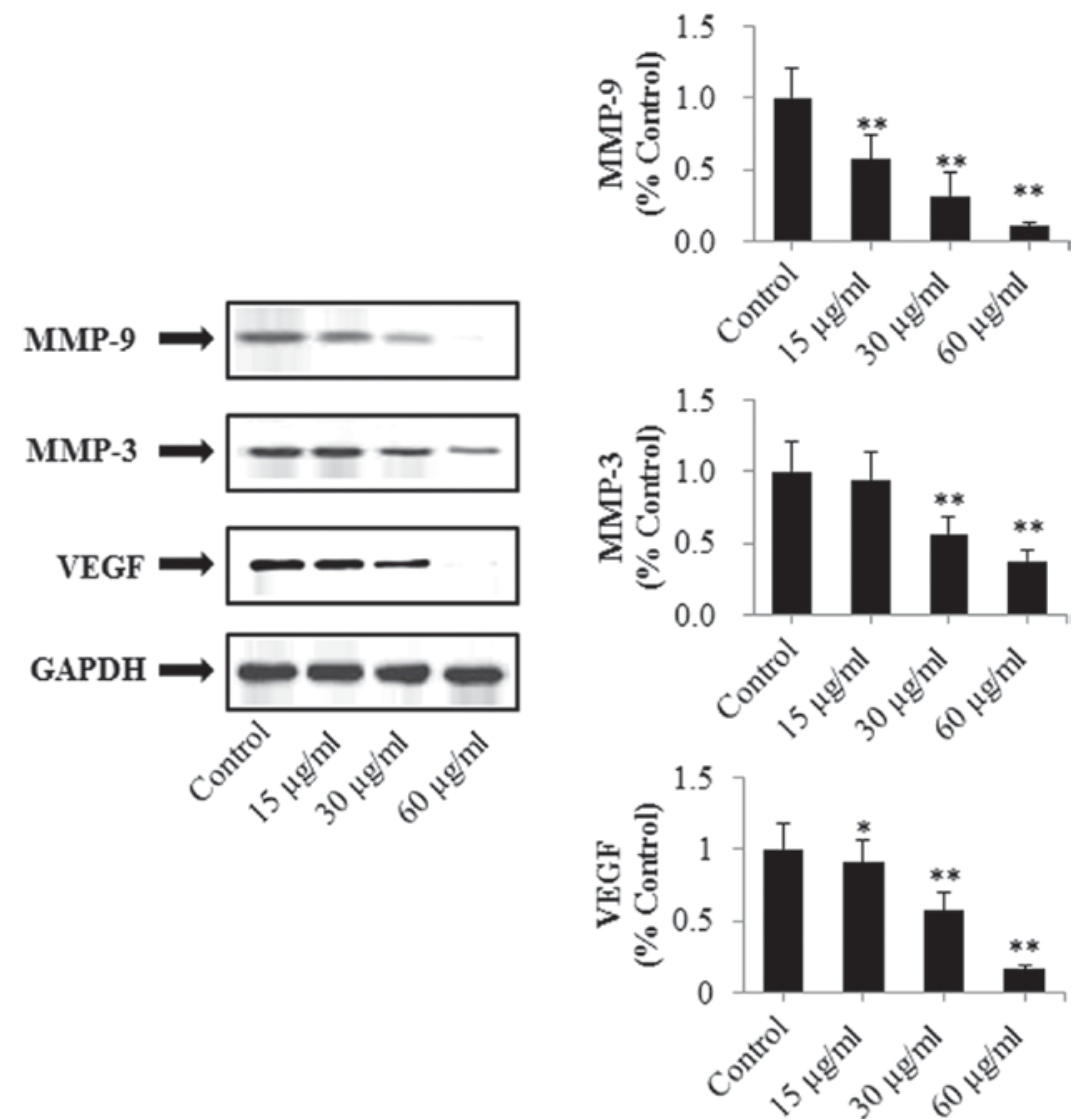

Figure 8. Regulatory effects of PRX on MMP-3, MMP-9 and VEGF. Cells were treated with PRX for $24 \mathrm{~h}$, following which total proteins were extracted and subjected to western blot assays. GAPDH was used as an internal control. Data are expressed as the mean \pm standard deviation $(\mathrm{n}=4)$. ${ }^{*} \mathrm{P}<0.01$ and ${ }^{* *} \mathrm{P}<0.01$ vs. Control. PRX, puerarin 6"-O-xyloside; MMP, matrix metalloproteinase; VEGF, vascular endothelial growth factor.

metastasis. MMP-9, activated by MMP-3, can destroy and degrade ECM on the surface of the tumor, and eventually accelerate the invasion and metastasis of the tumor (28). In addition, MMP-9 promotes the growth and diffusion of tumors (28). It has been reported that VEGF is one of the key components of wound healing by promoting angiogenesis (29). VEGF can promote the formation of MMPs and the growth and metastasis of tumor via accelerating the formation of new vessels (30). Therefore, the expression of MMP-3, MMP-9 and VEGF can be used to determine the possibility of growth and metastasis of tumors. In the present study, the results showed the downregulation of MMP-3, MMP-9 and VEGF, indicating that PRX inhibited SW480 colon cancer cell invasion and metastasis.

In conclusion, the present study demonstrated that PRX exerted notable antitumor effects against colon cancer cell lines through the induction of mitochondria-mediated intrinsic apoptosis, and inhibition of tumor invasion and metastasis

\section{Acknowledgements}

Not applicable.

\section{Funding}

The present study was supported by Zhejiang Provincial Natural Science Foundation (grant no. LY12H27009).

\section{Availability of data and materials}

The datasets used and/or analyzed during the current study are available from the corresponding author on reasonable request.

\section{Authors' contributions}

BBW conceived and designed the study; XLZ and JSM performed the experiments; XLZ and BBW analyzed the data; BBW and XLZ wrote the manuscript.

\section{Ethics approval and consent to participate}

Not applicable.

\section{Consent for publication}

Not applicable.

\section{Competing interests}

The authors declare that they have no competing interests.

\section{References}

1. Global Burden of Disease Cancer Collaboration, Fitzmaurice C, Dicker D, Pain A, Hamavid H, Moradi-Lakeh M, MacIntyre MF, Allen C, Hansen G, Woodbrook R, et al: The Global Burden of Cancer 2013. JAMA Oncol 1: 505-527, 2015. 
2. Jemal A, Bray F, Center MM, Ferlay J, Ward E and Forman D: Global cancer statistics. CA Cancer J Clin 61: 69-90, 2011.

3. Ferlay J, Soerjomataram I, Dikshit R, Eser S, Mathers C, Rebelo M, Parkin DM, Forman D and Bray F: Cancer incidence and mortality worldwide: Sources, methods and major patterns in GLOBOCAN 2012. Int J Cancer 136: E359-E386, 2015.

4. Daaboul HE, Daher CF, Bodman-Smith K, Taleb RI, Shebaby WN, Boulos J, Dagher C, Mroueh MA and El-Sibai M: Antitumor activity of $\beta$-2-himachalen-6-ol in colon cancer is mediated through its inhibition of the PI3K and MAPK pathways. Chem Biol Interact 275: 162-172, 2017.

5. Cragg GM and Newman DJ: Plants as a source of anti-cancer agents. J Ethnopharmacol 100: 72-79, 2005.

6. Chen R, Xue J and Xie M: Puerarin prevents isoprenaline-induced myocardial fibrosis in mice by reduction of myocardial TGF- $\beta 1$ expression. J Nutr Biochem 23: 1080-1085, 2012.

7. Zhou YX, Zhang $\mathrm{H}$ and Peng C: Puerarin: A review of pharmacological effects. Phytother Res 28: 961-975, 2014.

8. Wang Q, Wu T, Chen X, Ni J, Duan X, Zheng J, Qiao J, Zhou L and Wei J: Puerarin injection for unstable angina pectoris. Cochrane Database Syst Rev 19: CD004196, 2006.

9. Song W, Li YJ, Qiao X, Qian Y and Ye M: Chemistry of the Chinese herbal medicine Puerariae Radix (Ge-Gen): A review. J Chin Pharm Sci 23: 347-360, 2014.

10. Chen T, Chen H, Wang Y and Zhang J: In vitro and in vivo antitumour activities of puerarin 6"-O-xyloside on human lung carcinoma A549 cell line via the induction of the mitochondria-mediated apoptosis pathway. Pharm Biol 54: 1793-1799, 2016.

11. Fokunang CN, Ndikum V, Tabi OY, Jiofack RB, Ngameni B, Guedje NM, Tembe-Fokunang EA, Tomkins P, Barkwan S, Kechia Fz, et al: Traditional medicine: Past, present and future research and development prospects and integration in the national health system of Cameroon. Afr J Tradit Complement Altern Med 8: 284-295, 2011.

12. Xie Q, Yang Y, Wang Z, Chen F, Zhang A and Liu C: Resveratrol-4-O-D-(2'-galloyl)-glucopyranoside isolated from Polygonum cuspidatum exhibits anti-hepatocellular carcinoma viability by inducing apoptosis via the JNK and ERK pathway. Molecules 19: 1592-1602, 2014.

13. Mattern J and Volm M: Imbalance of cell proliferation and apoptosis during progression of lung carcinomas. Anticancer Res 24 4243-4246, 2004.

14. Liu YL, Tang LH, Liang ZQ, You BG and Yang SL: Growth inhibitory and apoptosis inducing by effects of total flavonoids from Lysimachia clethroides Du by in human chronic myeloid leukemia K562 cells. J Ethnopharmacol 131: 1-9, 2010.

15. Kroemer G, Galluzzi L, Vandenabeele P, Abrams J, Alnemri ES Baehrecke EH, Blagosklonny MV, El-Deiry WS, Golstein P, Green DR, et al: Classification of cell death: Recommendations of the nomenclature committee on cell death. Cell Death Differ 16: 3-11, 2009.

16. Okada $\mathrm{H}$ and Mak TW: Pathways of apoptotic and non-apoptotic death in tumor cells. Nat Rev Cancer 4: 592-603, 2004.

17. Yu P, Shi L, Song M and Meng Y: Antitumor activity of paederosidic acid in human non-small cell lung cancer cells via inducing mitochondria-mediated apoptosis. Chem Biol Interact 269: $33-40,2017$
18. Xu J, Jiang S, Li Y, Li M, Cheng Q, Zhao D, Yang B, Jia Z, Wang L and Song L: Caspase-3 serves as an intracellular immune receptor specific for lipopolysaccharide in oyster Crassostrea gigas. Dev Comp Immunol 61: 1-12, 2016.

19. Gao N, Budhraja A, Cheng S, Yao H, Zhang Z and Shi X: Induction of apoptosis in human leukemia cells by grape seed extract occurs via activation of c-Jun NH2-terminal kinase. Clin Cancer Res 15: 140-149, 2009.

20. Yang XK, Xu MY, Xu GS, Zhang YL and Xu ZX: In vitro and in vivo antitumor activity of scutebarbatine $A$ on human lung carcinoma A549 cell lines. Molecules 19: 8740-8751, 2014.

21. Peng W, Wu JG, Jiang YB, Liu YJ, Sun T, Wu N and Wu CJ: Antitumor activity of 4-O-(2"-O-acetyl-6"-O-p-coumaroyl- $\beta$ -D-glucopyranosyl)-p-coumaric acid against lung cancers via mitochondrial-mediated apoptosis. Chem Biol Interact 233: 8-13, 2015.

22. Chipuk JE, McStay GP, Bharti A, Kuwana T, Clarke CJ, Siskind LJ, Obeid LM and Green DR: Sphingolipid metabolism cooperates with BAK and BAX to promote the mitochondrial pathway of apoptosis. Cell 148: 988-1000, 2012.

23. Budhraja A, Gao N, Zhang Z, Son YO, Cheng S, Wang X, Ding S, Hitron A, Chen G, Luo J and Shi X: Apigenin induces apoptosis in human leukemia cells and exhibits anti-leukemic activity in vivo. Mol Cancer Ther 11: 132-142, 2012.

24. Dhanasekaran DN and Reddy EP: JNK signaling in apoptosis. Oncogene 48: 6245-6251, 2008.

25. Wang K, Zhang C, Bao J, Jia X, Liang Y, Wang X, Chen M, Su H, Li P, Wan JB and He C: Synergistic chemopreventive effects of curcumin and berberine on human breast cancer cells through induction of apoptosis and autophagic cell death. Sci Rep 6: 26064, 2016

26. Jiang Y, Goldberg ID and Shi YE: Complex roles of tissue inhibitors of metalloproteinases in cancer. Oncogene 21: 2245-2252, 2002.

27. Vihinen P,Ala-aho R and Kähäri VM: Matrix metalloproteinases as therapeutic targets in cancer. Curr Cancer Drug Targets 5: 203-220, 2005

28. Luo HZ, Huang ZH, Yu YL, Chen H, Zhou SH and Deng QY: Expression of MMP-9 in colon cancer and its clinical significance. J Oncol 15: 552-553, 2009.

29. Traub S, Morgner J, Martino MM, Höning S, Swartz MA, Wickström SA, Hubbell JA and Eming SA: The promotion of endothelial cell attachment and spreading using FNIII10 fused to VEGF-A165. Biomaterials 34: 5958-5968, 2013.

30. Zhang ZG and Zhu HG: Vascular endothelial growth factor (VEGF) and pancreatic cancer. J Dig Surg 4: 149-151, 2005.

(i) $\Theta$ This work is licensed under a Creative Common cc) Attribution-NonCommercial-NoDerivatives 4.0 International (CC BY-NC-ND 4.0) License. 